\section{Infección por Mycobacterium bovis en humanos en diez países de América Latina, 1970-2007}

La mayoría de los rebaños de ganado en América Latina se encuentran en zonas donde aún se informan casos de tuberculosis (TB). Por consiguiente, las personas que viven en esas áreas se encuentran en riesgo de infección, especialmente donde no hay un adecuado control sanitario y veterinario. Los métodos más utilizados para el diagnóstico de pacientes con TB siguen siendo el examen microscópico de frotis y el cultivo de laboratorio. Sin embargo, muchos de los medios empleados para el diagnóstico contienen glicerol, que inhibe el crecimiento de la mayoría de las cepas de Mycobacterium bovis.

En este trabajo se presenta un estimado -tomando en cuenta las posibles limitacionesde la importancia relativa de la TB por $M$. bovis en humanos en 10 países de la región (Argentina, Brasil, Chile, Colombia, Costa Rica, Ecuador, Perú, República Dominicana, Uruguay y Venezuela), con especial referencia al período 2000-2006. Para ello se analizaron los artículos publicados y los informes presentados entre 1970 y 2007, así como los informes de la OMS, la OPS, la FAO y otros organismos internacionales sobre los casos de TB en bovinos y humanos. Además, se envió un cuestionario a los laboratorios de los países estudiados (excepto Chile).

En la mayoría de los países no hay programas de diagnóstico y erradicación de TB por $M$. bovis y solo cuatro de los países estudiados informaron casos en humanos confirmados por métodos bacteriológicos. La mayoría de esos casos se detectaron en Argentina, donde el promedio de infección por $M$. bovis con respecto a $M$. tuberculosis varió de $0,34 \%$ a $1,00 \%$ entre 2000 y 2006, en dependencia de la zona. Se observó una tendencia a disminuir lentamente el número de casos en Buenos Aires, independientemente de la presencia o no de la infección por el VIH o el sida. En la mayoría de los países, la baja cobertura del diagnóstico por cultivo - especialmente con medios sin glicerol que contenían piruvato, más apropiados para el aislamiento de $M$. bovis - contribuye a subestimar la magnitud del problema.

La proporción de casos humanos de TB por M. bovis en los 10 países estudiados representó entre $0 \%$ y $2,5 \%$ de los casos de TB por M. tuberculosis. Con excepción de tres casos informados en Brasil, dos en Ecuador y uno en Venezuela, todos los casos de TB por M. bovis en humanos se diagnosticaron en Argentina. Esto puede deberse a que en este último país se emplean en mayor medida los medios Stonebrink y LJ, más aptos para el cultivo de esta micobacteria. No se han aislado casos de $M$. bovis en humanos en Chile, Colombia, Costa Rica, Perú, República Dominicana y Uruguay, pero esto puede deberse a que emplean medios de cultivo menos apropiados para esa micobacteria.

En países como Perú, donde la incidencia de TB es relativamente alta y donde hay una red bien organizada de laboratorios para el diagnóstico de esta enfermedad, se deben introducir medios de cultivo con piruvato, al menos en investigaciones específicas diseñadas para determinar la contribución real de $M$. bovis en la TB en humanos.

Los datos indican que la importancia de la infección por M. bovis como causa de TB en humanos continúa siendo menor que por $M$. tuberculosis en los países estudiados; no se han observado incrementos en la tasa de infección por M. bovis en los últimos años. No obstante, en varios países se confirmaron casos de TB provocados por esta micobacteria en humanos. Las principales medidas para el control, eliminación y posible erradicación de esta infección en humanos continúan siendo la higienización de los alimentos, la pasteurización de la leche, el control sanitario, la vigilancia epidemiológica y el tratamiento adecuado de los pacientes. (De Kantor IN, Ambroggi M, Poggi S, Morcillo N, Da Silva Telles MA, Osorio Ribeiro M, et al. Human Mycobacterium bovis infection in ten Latin American countries. Tuberculosis. 2008; en prensa.) 